\title{
Faktor - Faktor Yang Berpengaruh Terhadap Daya SaingBuahApel Khas Aceh di Kota Langsa
}

\author{
Dhian Rosalina ${ }^{*}$ \\ M. Rizqi Zati ${ }^{2}$ \\ Murdhiani $^{3}$ \\ Kartika Yuliari ${ }^{4}$ \\ 1,2Fakultas Ekonomi Universitas Samudra, Langsa \\ ${ }^{3}$ Fakultas Pertanian Universitas Samudra, Langsa \\ ${ }^{4}$ Fakultas Ekonomi Universitas Kadiri, Kediri \\ *email:dhian.rosalina@unsam.ac.id
}

Diterima: Juni 2020, Disetujui: September 2020, Dipublish: Oktober 2020

\begin{abstract}
Abstrak
Buah Apel Aceh merupakan hasil dari konsep kawin silang mentimun dan melon, dengan bentuk menyerupai apel dengan warna khas putih, dan rasa manis khas menyerupai buah melon dan metimun. Apel Aceh belum banyak dikenal secara nasional, dengan pemasaran yang masih terbatas yakni sampai dengan Palembang, dikarenakan pembudidaya apel aceh masih sedikit dan belum populer untuk dikembangkan. Apel aceh memiliki potensi secara ekonomi untuk dikembangkan baik berupa buah segar maupun olahan, karena merupakan salah buah khas yang mudah ditemukan di Aceh.Tujuan dari penelitian ini adalah menganalisis faktor - faktor apakah yang mempengaruhi daya saing apel khas aceh, menganalisis faktor apakah yang dominan mempengaruhi daya saing apel khas aceh, ditinjau dari persepsi konsumen.Metode Penelitian ini menggunakan pendekatan Confirmatory Factor Analysis (CFA), populasi dalam penelitian ini adalah warga Kota Langsa yang sedang berada di sejumlah supermarket dan pasar tradisional, jumlah responden adalah 100 orang dengan metode purposive sampling. Hasil dari penelitian ini adalah dari delapan item yang berpengaruh terhadap daya saing apel khas Aceh, terbentuk menjadi dua faktor utama yaitu faktor kualitas buah dan faktor harga dengan pengaruh mencapai lima puluh persen. Dan faktor kualitas buah mempunyai pengaruh dominan dengan skor eigenvalue dua koma lima enam.
\end{abstract}

Kata Kunci: Confirmatory Factor Analysis, Daya saing, Apel Aceh

\begin{abstract}
Apples from Aceh are the result of the concept of interbreeding cucumbers and melons, with an apple-like shape with a distinctive white color, and a distinctive sweet taste resembling melons and metimuns. Aceh apples are not as well-known as other apples because the market is still limited to Palembang, another reason is because of the lack of Aceh apple cultivators. Aceh apples have economic potential, both in the form of fresh and processed fruit, because it is one of the fruits that is easily found in Aceh. The purpose of this study is 1) Analyzing factors affecting Apple's Competitiveness from Aceh, 2) Analyzing which factors dominant affect the competitiveness of Aceh apple based on consumer perceptions. This research method uses the Confirmatory Factor Analysis (CFA) approach, the number of respondents is 100 people with a purposive sampling method. The results of this study are of the eight items that affect the competitiveness of Aceh's typical apples, there are two main factors namely the fruit quality factor and the price factor with the effect reaching $52.86 \%$. And the fruit quality factor has a dominant influence with an eigenvalue score of 2.566 .
\end{abstract}

Keyword: Confirmatory Factor Analysis, Competitiveness, Aceh Apple 


\section{PENDAHULUAN}

Bergabungnya Indonesia dalam berbagai lembaga Internasional seperti Asean China Free Trade Agreement (ACFTA) pada tahun 2002, Asean Free Trade Area (AFTA) di tahun 2004 menghasilkan konsekuensi keterbukaan negara terhadap produk impor yang akhirnya membanjiri pasar Indonesia. Salah satu pemicu utamanya adalah penurunan tarif sampai dengan 5\% bagi semua komoditas, termasuk di dalamnya buah buahan (Anggasari, dkk.,2013). Indonesia dengan dengan jumlah penduduk lebih dari 23 juta jiwa, sehingga menjadikannya sebagai salah satu pasar potensial di dunia. Kondisi tersebut tentunya membuka peluang bagi perusahaan multinasional di dunia untuk masuk ke Indonesia, termasuk di dalamnya komoditi hortikultura. Salah satu jenis buah yang digemari oleh masyarakat indonesia adalah buah apel, buah apel di indonesia sendiri dikuasai oleh negara negara subtropis seperti Tiongkok (50\%), Amerika Serikat (38\%), Prancis (10\%), dan sisanya diimpor dari negara Australia, Jepang, dan Selandia Baru (Finance.Detik.com, 2019) meliputi jenis apel royal gala, fuji, granny smith, dan apel merah. dengan bergamnya aneka jenis buah apel di pasar, akan mempengaruhi sikap dan pilihan konsumen dalam melakukan pembelian. (Rahmawati., et al, 2018). Sikap konsumen yang positif terhadap atribut yang ada didalam produk akan mendorong konsumen untuk membeli produk tersebut. Dengam melihat bahwa buah apel impor mendominasi pasar, maka menjadi tantangan bagi produk buah lokal agar dapat merebut pasar indonesia sendiri yang sangat besar. Sampai saat ini, apel lokal masih dipasok dari Kota Malang, Jawa timur yang hanya mampu memenuhi kurang dari $10 \%$ permintaan buah apel di pasaran (Finance.Detik.com, 2019). Buah Apel Aceh merupakan hasil dari konsep kawin silang mentimun dan melon (Analisadaily.com, 2019), dengan bentuk menyerupai apel dengan warna khas putih, dan rasa manis khas menyerupai buah melon dan metimun dengan harga 30 sampai 35 ribu per kilo. Apel Aceh banyak ditanam di Kabupaten Pidie,Pidie jaya, dan Kota langsa dengan masa panen empat bulan sekali. Apel Aceh belum banyak dikenal secara nasional, dengan pemasaran yang masih terbatas yakni sampai dengan Palembang, dikarenakan pembudidaya apel aceh masih sedikit dan belum populer untuk dikembangkan.

Studi mengenai sikap dan perilaku konsumen merupakan salah satu cara untuk meningkatkan daya saing (Rahmawati, et al,2018). Perilaku konsumen buah buahan perlu dipahami agar dapat memasarkan hasil panen dengan tepat sasaran 
(Anggasari, et al., 2013). Studi yang dilakukan oleh Bytyqi, et al,(2015) bahwa konsumen bersedia membayar lebih mahal untuk produk buah lokal. Kajian mengenai sudut pandang konsumen mengenai bagaimana buah apel aceh dapat bersaing dan memenuhi permintaan di pasar dalam negeri diperlukan karena berpengaruh terhadap banyak aspek dimulai dari kesejahteraan petani apel aceh, mengurangi dominasi buah impor, dan memperkaya pilihan buah buahan bagi masyarakat secara umum.

Tujuan penelitian ini adalah sebagai berikut : pertama, menganalisis faktor - faktor apakah yang mempengaruhi daya saing apel khas aceh, kedua,menganalisis faktor apakah yang dominan mempengaruhi daya saing apel khas aceh, ditinjau dari persepsi konsumen

\section{METODE PENELITIAN}

Penelitian ini menggunakan pendekatan Confirmatory Factor Analysis (CFA) untuk mencari faktor faktor yang membentuk daya saing apel khas aceh. Analisis faktor digunakan oleh peneliti agar dapat mengindentifikasi dimensi struktur sampai dengan seberapa jauh variabel dijelaskan oleh setiap dimensi (Imam Ghazali, 2003).

Populasi dalam penelitian ini adalah penduduk Kota Langsa yang sedang berbelanja dan berada di sejumlah supermarket dan pasar tradisional, yang kemudian diambil sebagai sampel penelitian berjumlah 100 orang responden yang memiliki kriteria sebagai berikut : 1) Responden berusia minimal 17 tahun, 2) Responden pernah membeli dan mengkonsumsi langsung buah apel aceh.Terdapat delapan item pernyataan dalam kuesioner penelitian ini, yang mana pernyataan tersebut antara lain sebagai berikut: 1) Harga buah apel aceh yang terjangkau, 2) Rasa buah apel aceh yang manis dan segar, 3)ukuran buah apel aceh yang pas, 4) Warna buah apel aceh yang segar/tidak pucat ,5) Kondisi buah yang segar, 6) Aroma apel aceh yang harum, 7) Tekstur buah apel aceh cukup lembut, 8) Buah apel aceh mengandung berbagai vitamin.

Skala digunakan untuk mengukur data interval pada kuesioner ini adalah dengan skala likert, dengan rentang 1 sampai dengan lima. Dimana skor 1 untuk opsi sangat tidak setuju sampai dengan skor 5 untuk opsi sangat setuju.

\section{HASIL DAN PEMBAHASAN}

Profil responden berdasarkan kategori usia dalam penelitian ini dibagi menjadi lima kelompok, yaitu 17 - 22 tahun, 23 - 28 tahun, 29 - 34 tahun, 35 - 40 tahun, dan kelompok usia diatas 40 tahun. Mayoritas responden yang melakukan 
pembelian buah apel adalah responden pada kelompok usia17 22 tahun, sebesar 46 persen. Pengelompokkan responden pada proses pengumpulan data, usia tersebut dikarenakan responden pada usia tersebut relative lebih mudah untuk berpartisipasi dalam wawancara dan pengisian angket yang dilakukan pada sejumlah pasar tradisional dan supermarket di Kota Langsa.

Berdasarkan hasil pengolahan data, tingkat pendidikan responden yang paling banyak adalah lulusan perguruan tinggi yang mencapai sebesar 52 persen. Hal ini menunjukkan bahwa responden dalam penelitian ini memiliki pendidikan yang cukup tinggi.Tingkat pendidikan seseorang dapat mempengaruhi keputusan pemilihan dan pembelian barang. Semakin tinggi pendidikan berdampak pada kesadaran akan kesehatan, sehingga berpengaruh terhadap proses pengambilan keputusan konsumen dalam mengonsumsi buah apel (Widiyanto et al., 2016).

\section{Analisis Deskriptif}

Peneliti menggunakan analisis deskriptif dengan alat ukur mean, dimana analisis deskriptif digunakan untuk medenskripsikan atau menggambarkan data yang telah terkumpul dalam proses penelitian (Sanusi, 2013). Statistik deskriptif digunakan untuk mendapatkan data tentang bobot rata rata jawaban seluruh responden terhadap setiap pernyataan pada masing masing variabel, maupun tiap dimensi dan indikator dari variabel tersebut (Yuwono et al., 2007). Berikut adalah hasil dari statistik deskriptif dalam penelitian ini :

Tabel 1.Hasil Analisis Statistik Deskriptif

\begin{tabular}{clrr}
\hline No & Faktor Pembentuk Daya Saing Apel Aceh & Mean & Std. Deviation \\
\hline 1 & Harga buah apel aceh yang terjangkau & 3.50 & 859 \\
2 & Rasa buah apel aceh yang manis dan segar & 2.87 & .906 \\
3 & Ukuran buah apel aceh yang pas & 3.23 & .790 \\
4 & Warna buah apel aceh yang segar/tidak pucat & 2.89 & 1.127 \\
5 & Kondisi buah yang segar & 3.98 & .829 \\
6 & Aroma apel aceh yang harum & 2.98 & 1.119 \\
7 & Tekstur buah apel aceh cukup lembut & 3.43 & .820 \\
8 & Buah apel aceh mengandung banyak vitamin & 3.40 & 1.005 \\
\hline
\end{tabular}

Sumber :data primer, 2020 (diolah) 
Berdasarkan dari hasil perhitungan mean, faktor nomor lima yaitu kondisi kesegaran buah memiliki skor tertinggi, yaitu 3,98 yang berarti responden memiliki persepsi bahwa faktor tersebut memiliki dampak besar terhadap daya saing buah apel khas Aceh. Sedangkan faktor nomor dua memiliki nilai terendah, adalah faktor rasa buah apel aceh yang manis dan segar, dimana faktor tersebut berdasarkan persepsi responden memiliki dampak atau pengaruh yang terendah dalam mempengaruhi daya saing buah apel Aceh.

Pada hasil skor standard deviasi terlihat bahwa, faktor nomor empat yaitu warna buah yang segar/tidak pucat memiliki skor tertinggi, yaitu 1,127. Artinya faktor tersebut dirasakan berbeda beda, atau tidak dirasakan secara sama oleh responden bahwa faktor tersebut mempunyai pengaruh terhadap daya saing buah apel Aceh. Kemudian, pada faktor nomor tiga yaitu ukuran buah apel aceh, memiliki standard deviasi terendah yakni 0,790 yang berarti bahwa faktor tersebut dirasakan atau diperspsikan sama secara merata oleh responden dalam mempengaruhi daya saing apel aceh.

\section{Uji Confirmatory Analysis}

Hasil uji Confirmatory test terdiri dari beberapa langkah berikut ini:

1. KMO dan Bartlett's Test

Konsistensi item terhadap item serta mengetahui pembentukan faktor baru dengan analisis faktor dilakukan pada setiap itemnya,(Imam Ghazali, 2003). KMO dan Bartlett's tests adalah pengujian yang digunakan untuk mengetahui apakah item tem yang menjadi obyek analisis layak dimasukkan dalam analisis faktor. Koefesien Kaiser-Meyer-Olkin (KMO) digunakan untuk mengukur sekaligus mengetahuikecukupan sampel yang digunakan.KMO Measure of Sampling Adequency dan Anti-image Matrices harus cukup kuat diatas 0,50 (Mahmudah, 2019). Hasil uji KMO (Kaiser-Mayer-Olkin) dalam penelitian ini adalah sebesar 0,646 dengan signifikansi 0.000, Sehingga, dengan demikian dapat disimpulkan bahwa analisis faktor dapatdilanjutkan.

1. Communality

Proses faktoring dan rotasi merupakan merupakan salah satu proses utama pada analisis faktor, yaitu dengan melakukan ekstraksi terhadap keseluruhan variabel yang ada sampai terbetuk satu atau lebih faktor (Yuwono et al., 2007). Semakin besar nilai extraksi sebuah variabel, berarti semakin erat hubungannya dengan faktor yang terbentuk (Yuwono et al., 2007). 
Tabel 2. Hasil Uji Communalities

\begin{tabular}{llc}
\hline \multicolumn{1}{c}{ Faktor } & Extraction \\
\hline 1. & Harga buah apel aceh yang terjangkau & .623 \\
2. Rasa buah apel aceh yang manis dan segar, & .630 \\
3. Ukuran buah apel aceh yang pas & .441 \\
4. Warna buah apel aceh yang segar/tidak pucat & .420 \\
5. Kondisi buah yang segar & .518 \\
6. Aroma apel aceh yang harum & .532 \\
7. Tekstur buah apel aceh cukup lembut & .451 \\
8. Buah apel aceh mengandung berbagai vitamin & .651 \\
\hline
\end{tabular}

Sumber : Data primer, 2020 (diolah)

Pada proses faktoring di atas, angka extraction tertinggi adalah pada kandungan vitamin pada buah apel aceh, yaitu sebesar 0,651artinya hubungan paling kuat terhadap pembentukan daya saing apel aceh ditunjukkan pada persepsi terhadap kandungan vitamin buah apel aceh sebesar 65\%, atau dengan kata lain $65 \%$ varians dapat dijelaskan pada item kandungan vitamin apel aceh. Sedangkan faktor ukuran buah apel aceh yang pas memiliki hubungan yang paling lemah yaitu 0,441 sekitar $44 \%$ varians dapat dijelaskan oleh faktor tersebut. Dengan demikian, pengujian untuk menentukan faktor - faktor yang daya saing buah apel Aceh dapat dilakukan melalui pengintisarian faktor yang telah diuji tersebut.

2. Eigenvalue

Berdasarkan hasil ekstraksi SPSS, hasil dari pengujian menghasilkan tiga faktor yang dapat dilihat pada tabel berikut ini di bawah :

Tabel 3.Hasil Total Variance Explained

\begin{tabular}{cccc}
\hline Komponen & \multicolumn{3}{c}{ Initial Equivalent } \\
\cline { 2 - 4 } & Total & \% of Variance & Cumulative \% \\
\hline 1 & 2.566 & 32.073 & 32.073 \\
2 & 1.663 & 20.793 & 52.866 \\
3 & .952 & 11.904 & 64.770 \\
4 & .839 & 10.490 & 75.260 \\
5 & .606 & 7.578 & 82.838 \\
6 & .566 & 7.077 & 89.915 \\
7 & .482 & 6.028 & 95.943 \\
8 & .325 & 4.057 & 100.000 \\
\hline
\end{tabular}

Sumber : Data primer, 2020 (diolah)

Dari skor eigenvalue, dapat dilihat bahwa terdapat dua faktor yang terbentuk.Hal ini disebabkan karena pada faktor ke tiga, total eigenvalue sudah berada dibawah satu, yaitu sebesar 0,952. Dengan demikian, proses faktoring terhenti pada dua faktor saja, dengan nilai percent of variance $52,86 \%$ yang berarti kedua faktor tersebut mampu menjelaskan variabilitas ke delapan variabel yang asli. 
Tabel 4. Hasil Analisis Faktor Loading

\begin{tabular}{llcc}
\hline & & \multicolumn{2}{c}{ Component } \\
& & 1 & 2 \\
\hline 1. Harga buah apel aceh yang terjangkau & .257 & .746 \\
2. Rasa buah apel aceh yang segar & .775 & -.170 \\
3. Ukuran buah yang pas & .234 & .622 \\
4. Warna buah apel aceh yang segar/tidak pucat & .640 & -.107 \\
5. Kondisi buah yang segar & .247 & .676 \\
6. Aroma apel aceh yang harum & .615 & -.392 \\
7. Tekstur apel Aceh yang lembut & .654 & .151 \\
8. Buah apel Aceh mengandung banyak vitamin & .754 & -.215 \\
\hline
\end{tabular}

3. Faktor Loading

Setelah memperoleh skor eigenvalue, langkah berikutnya adalah melakukanpenamaan terhadap faktorfaktor yang terbentuk dalam analisis faktor dapat dilakukan dengan dua cara (Pradana, Slamet, \& Andrianto, 2018), yaitu pemberian nama faktor yang merepresentasikan nama-nama variabel yang membentuk faktor tersebut dan yang kedua adalah penamaan faktor berdasarkan variabel yang memiliki nilai.

Sebelum melakukan penamaan dari faktor, maka terlebih dahulu melakukan klasifikasi dari setiap variabel apakah termasuk dalam faktor 1 dan 2, untuk klasifikasi tersebut maka perlu melakukan analisis table rotated componenet matrix. Berikut penjelasan identifikasi variabel yang berkorelasi dengan faktor satu dan dua:

a. Variabel 1, yaitu harga buah apel aceh yang terjangkau termasuk dalam faktor 2, karena faktor loading terbesar adalah 0,746

b. Variabel 2, yaitu rasa buah apel aceh yang segar termasuk dalam faktor 1, dengan faktor loading terbesar 0,775

c. Variabel 3, yaitu ukuran buah yang pas termasuk dalam faktor 2, dengan faktor loading 0,622

d. Variabel 4, yaitu warna buah apel aceh yang segar/tidak pucat, termasuk dalam faktor 1 , dengan faktor loading 0,640

e. Variabel 5, yaitu kondisi buah yang segar, dengan faktor loading 0,676 masuk pada faktor 2

f. Variabel 6, yaitu aroma apel aceh , termasuk dalam faktor 1 , dengan faktor loading terbesar 0,615

g. Variabel 7, tekstur apel aceh yang lembut, termasuk dalam faktor 1 , dengan faktor loading 0,654

h. Variabel 8, buah apel aceh mengandung vitamin, masuk dalam faktor 1 dengan faktor loading 0,754

Berdasarkan hasil dari rangkaian analisis faktor tersebut di atas, maka dari ke delapan factor tersebut mengerucut menjadi dua faktor yang berpengaruh terhadap daya saing apel aceh. Yaitu :

a. Faktor 1 terdiri dari :

1) Rasa buah apel aceh

2) Warna apel aceh

3) Aroma apel aceh

4) Tekstur buah apel aceh

5) Kandungan vitamin apel aceh

Hal ini konsisten dengan penelitian 
yang dilakukan oleh Nurdin \& Damayanti, (2017); Pradana et al., (2018) bahwa rasa, warna, aroma, tekstur dan kandungan vitamin berpengaruh terhadap minat konsumen untuk melakukan pembelian yang berarti merupakan daya saing dari komoditas buah tersebut. Oleh karena itu, untuk selanjutnya faktor satu diberi namafaktor kualitas buah.

b. Faktor 2 terdiri dari :

1) Harga buah apel aceh

2) Ukuran buah apel aceh

3) Kondisi buah apel aceh

Hal ini konsisten dengan penelitian Felixs \& Palit, (2013); Nurdin \& Damayanti, (2017) bahwa bahwa faktor harga, ukuran dan kondisi buah merupakan faktor daya saing dari buah buahan di pasar. Untuk selanjutnya faktor ke dua diberi namafaktor harga.

Dari hasil analisis data di atas, mengacu pada table tiga, nilai eigenvalue terbesar adalah pada faktor satu yaitu factor kualitas buah dengan skor 2,566 yang berarti bahwa faktor dominan yang mempengaruhi daya saing apel khas Aceh adalah faktor kualitas buah.

\section{SIMPULAN}

Kesimpulan dari penelitian ini adalah terdapat dua factor yang mempengaruhi daya saing apel khas aceh yaitu pertama,faktor kualitas buah yang terdiri dari rasa buah, warna, tekstur, kandungan vitamin, dan aroma buah apel aceh. Kedua, faktor harga yang terdiri dari harga buah, ukuran, dan kondisi buah. Dari penelitian ini menunjukkan daya saing apel aceh mendapatkan pengaruh dari kedua faktor tersebut sampai dengan $52,8 \%$, yang mana sisanya dipengaruhi oleh faktor lain diluar penelitian ini. Perlu adanya inovasi pengolahan produk apel aceh untuk dapat lebih dikenal masyarakat luas, seperti menjadi bentuk makanan dan minuman lain antara lain dalam bentuk jus buah, rujak, dan lain sebagainya. Sehingga buah apel aceh (yang sebagian masyarakat menyebut sebagai lemon aceh) dapat menjadi alternatif konsumsi buah bagi masyarakat selain dalam bentuk konsumsi langsung.

\section{DAFTAR PUSTAKA}

Analisadaily.com. (2019). Apel Aceh Banjiri Kota Medan. Retrieved from http://news.analisadaily.com/read /apel-aceh-banjiri-kota-medan-dibulanramadan/242709/2016/06/09

Anggasari, P., Yuliati, L. N., \& Retnaningsih. (2013). Pengaruh Ethnosentrisme Terhadap Sikap, Preferensi Dan Perilaku Pembelian Buah Lokal Dan Impor. Jurnal Manajemen Dan Agribisnis, 10(2), 128-136.

Bytyqi, N., Skreli, E., Verçuni, A., Imami, D., \& Zhllima, E. (2015). Analyzing consumers' preferences for apples in Pristina, Kosovo. Bodenkultur, 66(1-2), 61-69.

Felixs, D., \& Palit, H. C. (2013). Analisa Persepsi dan Preferensi Kualitas Buah Tropis. 1(1), 77-82.

Finance.Detik.com. (2019). Pasar Buah Apel Negeri Dikuasai Impor. Retrieved from 
https://finance.detik.com/beritaekonomi-bisnis/

Imam Ghazali. (2003). Analisis Multivariate Dengan Menggunakan SPSS (dua). Semarang: Badan Penerbit Universitas Diponegoro.

Mahmudah, N. (2019). Analisis FaktorFaktor Yang Mempengaruhi Minat Mahasiswa STEI SEBI Jurusan Akuntansi Syariah terhadap Profesi Akuntan Publik. Jurnal Akuntansi Dan Keuangan Islam, 2(1), 83-100.

Nurdin, M. F., \& Damayanti, L. (2017). Pengaruh Preferensi Konsumen Terhadap Pembelian Buah Apel Impor Di Hypermart Palu Grand Mall. Agroland, 24(2), 103-112.

Pradana, A. K., Slamet, A. S., \& Andrianto, M. S. (2018). Analisis faktor yang memengaruhi pengambilan keputusan pembelian pepaya Calina. Jurnal Manajemen, 9(2), 155.

Rahmawati, Dianah Umi; Antara, Made; Suryawardani, O. (2018). Sikap
Konsumen terhadap Atribut Buah Jeruk Lokal dan Impor di Kota Denpasar. E-Jurnal Agribisnis Dan Agrowisata, 7(2), 222-231.

Sanusi, A. (2013). Metodologi Penelitian Bisnis (1st ed.). Jakarta: Salemba Empat.

Sudiyarto. (n.d.). Sikap Kepercayaan Konsumen Sebagai Tolok Ukur Daya Saing Antara Buah Apel Lokal dan Impor. Fakultas Pertanian UPN "Veteran"Jawa Timur.

Widiyanto, N. A., Adhi, A. K., \& Daryanto, H. K. (2016). Atribut - Atribut yang Mempengaruhi Sikap dan Preferensi Konsumen Dalam Membeli Buah Apel di Kota Surabaya dan Kota Malang, Provinsi Jawa Timur. 9(2), 136-146.

Yuwono, R., Retno, R. R., Bisnis, P. M., Manajemen, P. S., Petra, U. K., \& Siwalankerto, J. (2007). Analisa Faktor-Faktor Penghambat Pertumbuhan Di Jawa Timur. 1(3). 